\title{
Effects of Enhancing Micromixing on Nucleation/Crystal Growth Process and Material Properties of Zeolite
}

\author{
Tingting $\mathrm{Qi}^{1}$, Jing $\mathrm{Shi}^{2}$, Xishuo Wang ${ }^{1}$, Kun Dong ${ }^{1}$, Yong Luo $^{1}$, Jiawei Teng ${ }^{2}$, Guang-Wen \\ $\mathrm{Chu}^{1}$, Liangliang Zhang ${ }^{1}$, Hai-Kui Zou ${ }^{1}$, and Baochang Sun ${ }^{1}$ \\ ${ }^{1}$ Beijing University of Chemical Technology College of Chemical Engineering \\ ${ }^{2}$ State Key Laboratory of Green Chemical Engineering and Industrial Catalysis, SINOPEC \\ Shanghai Research Institute of Petrochemical Technology, Shanghai 201208, China
}

June 26, 2020

\begin{abstract}
Hierarchical (micro/mesopore) ZSM-5 zeolites were hydrothermally synthesized with enhancing micromixing of the high viscosity reaction system in a rotating packed bed (RPB). Herein, the effects of four operating processes with different micromixing intensity on nucleation/crystal growth process as well as properties of ZSM-5 zeolites were investigated. Results indicated that enhancing micromixing by RPB in the zeolite synthesis could facilitate the formation of $\mathrm{Al}$ sites and shorten the nucleation and crystallization period. ZSM-5 samples prepared by the RPB premix process exhibit hierarchical structure, smaller average particle size, more uniform particle size distributions, larger specific surface areas, higher catalytic stability as well as more Brønsted and Lewis acid sites. While adopting the prepared ZSM-5 zeolites with RPB premix for catalyzing C4-olefin cracking reaction, the conversion of $\mathrm{C} 4$-olefin and yield of propylene were higher than that obtained by traditional stirring tank reactor premix.
\end{abstract}

Effects of Enhancing Micromixing onNucleation/Crystal Growth Process and Material Properties of Zeolite

Tingting Qi ${ }^{\mathrm{a}, \mathrm{b}}$, Shi Jing ${ }^{\mathrm{c}}$, Xishuo Wang ${ }^{\mathrm{a}, \mathrm{b}}$, Kun Dong ${ }^{\mathrm{a}, \mathrm{b}}$, Yong Luo ${ }^{\mathrm{a}}$, Jiawei Teng ${ }^{\mathrm{c}, *}$, Guang-Wen Chu ${ }^{\text {a,b }}$, Liangliang Zhang ${ }^{\mathrm{a}}$, Hai-Kui Zou ${ }^{\mathrm{a}}$, Baochang Sun ${ }^{\mathrm{a}, *}$

${ }^{a}$ Research Center of the Ministry of Education for High Gravity Engineering and Technology,Beijing University of Chemical Technology, Beijing 100029, PR China

${ }^{b}$ State Key Laboratory of Organic-Inorganic Composites, Beijing University of Chemical Technology, Beijing, 100029, PR China

${ }^{c}$ State Key Laboratory of Green Chemical Engineering and Industrial Catalysis, SINOPEC Shanghai Research Institute of Petrochemical Technology, Shanghai 201208, China

* Corresponding author (Baochang Sun). E-mail: sunbc@mail.buct.edu.cn, Tel: 010-64443134-803, Address: No 15 Bei San Huan Dong Road, Beijing, 100029, China

* Corresponding author (Jiawei Teng). E-mail: tengjw.sshy@sinopec.com, Tel: 021-68467713, Address: No 1658 Pudong North Road, Shanghai, 201208, China

\section{ABSTRACT}

Hierarchical (micro/mesopore) ZSM-5 zeolites were hydrothermally synthesized with enhancing micromixing of the high viscosity reaction system in a rotating packed bed (RPB). Herein, the effects of four operating 
processes with different micromixing intensity on nucleation/crystal growth process as well as properties of ZSM-5 zeolites were investigated. Results indicated that enhancing micromixing by RPB in the zeolite synthesis could facilitate the formation of $\mathrm{Al}$ sites and shorten the nucleation and crystallization period. ZSM-5 samples prepared by the RPB premix process exhibit hierarchical structure, smaller average particle size, more uniform particle size distributions, larger specific surface areas, higher catalytic stability as well as more Brønsted and Lewis acid sites. While adopting the prepared ZSM-5 zeolites with RPB premix for catalyzing C4-olefin cracking reaction, the conversion of C4-olefin and yield of propylene were higher than that obtained by traditional stirring tank reactor premix.

KEYWORDS: ZSM-5 zeolites, Rotating packed bed, Nucleation/crystal growth mechanism, Al sites, C4olefin cracking reaction

\section{Introduction}

ZSM-5 zeolites with excellent catalytic performance have been widely applied in the petrochemical industry as shape-selective catalysts [1-4], such as methanol-to-aromatics reaction [5], methanol-to-olefins reaction [6], fluid catalytic cracking reaction [7], deep desulfurization [8] and so on. While their morphological, textural and acidic properties often affect catalytic performance, it remains a research focus to control the physical and chemical properties of zeolites.

In an attempt to improve the performance of zeolites, two routes have been proposed: (1) Tailoring acid sites in zeolites [9]. Various approaches have been developed to improve acid sites of zeolites including dealumiumazation [10,11], $\mathrm{SiO}_{2}$ deposition [12], the load of superacid [13], and so on. Dealuminization of zeolites prompts the aluminum species in the lattice to migrate out with high-temperature treatment, resulting in a transformation from framework aluminum to extra-framework aluminum. The formation of extra-framework aluminum is beneficial to increasing acid amount of Lewis acidity, and consequently, enhancing the synergistic effect of Brønsted and Lewis acidity [11]. The vapor deposition of $\mathrm{SiO}_{2}$ could facilitate the formation of framework aluminum in zeolites, resulting in an increase of the Brønsted acidity [12]. The load of superacid enhances both Brønsted acidity and Lewis acidity of zeolites [13]. However, the secondary high-temperature and acid treatment in the above processes often destroyed the pore structure and hydrothermal stability of zeolites [14]. (2) Decreasing particle sizes and donating mesopores or macropores to zeolites by adding templates in the reaction system or enhancing micromixing during the hydrothermal synthesis process [15]. Kim et al. [16] have prepared nanosized ZSM-5 zeolites with particle sizes in the range of 12-100 nm via confined-space synthesis using colloid-imprinted carbons as templates. Narayanan et al. [17] have synthesized microporous ZSM-5 zeolites with an average size of $340 \mathrm{~nm}$ by using nonionic surfactants (Triton X-100), and Dong et al. [18] have prepared large macropores (average pore-diameter: $1.5 \mu \mathrm{m}$ ) zeolite monoliths by the transformation of mesoporous silica spheres. On the other hand, enhancing micromixing in the nucleation/crystal growth period was reported to be a useful method for the fast synthesis of hierarchical zeolites [19]. During the nucleation process of zeolites, the uniformity of various reaction species affects the assembly of structural units, resulting in the differences of the size, amount, and composition of the crystal nucleus. According to the Ostwald ripening growth mechanism, a large crystal nucleus will grow up based on the disappearance of the small crystal nucleus. Thus, the morphological, textural, and acidic properties of the final crystal are closely related to the uniformity of the initial crystal nucleus.

In the traditional stirring tank reactor (STR), it's difficult to obtain a homogeneous nucleation environment and uniformity of initial crystal nucleus [20], particularly in high viscosities and large solution-volume systems [21, 22]. A rotating packed bed (RPB) as an efficient process intensification device can provide a high-gravity environment with considerable shear force, leading to the excellent micromixing effect [23-26]. During the ZSM-5 synthesis process, RPB can create reaction precursors with uniform concentration and supersaturation, resulting in uniform nucleation and consequently the acceleration of crystallization of zeolites [19]. Also, enhancing micromixing to improve acid strength and acid quantity by controlling $\mathrm{Al}$ contents during the nucleation/growth process of zeolite has not been extensively studied [27].

In this study, four operating processes, including RPB premix - dynamic crystallization, RPB premix - static 
crystallization, STR premix - dynamic crystallization, and STR premix - static crystallization, were carried out to investigate the effects of enhancing micromixing in the zeolite synthetic pathway on nucleation/crystal growth process and material properties of ZSM-5 zeolites. The nucleation/crystal growth mechanism of ZSM-5 zeolites was studied based on experimental data characterized by Fourier transform infrared (FTIR) spectrophotometry and powder X-ray diffraction (XRD). And the catalytic cracking reaction of $\mathrm{C} 4$ olefins was adopted for evaluating the catalytic performance of the prepared ZSM-5 zeolites obtained by different operating processes.

\section{Materials and methods}

\subsection{Chemicals}

Aluminum sulfate octadecahydrate $\left(\mathrm{Al}_{2}\left(\mathrm{SO}_{4}\right)_{3} \cdot 18 \mathrm{H}_{2} \mathrm{O}\right)$, silica sol (40 wt\% aqueous solution) and sodium chloride $(\mathrm{NaCl})$ were purchased from Aladdin Co., Ltd. Tetrapropylammonium hydroxide (TPAOH, 25 wt\% aqueous solution) was purchased from Innochem Co., Ltd. C4-olefin was provided from Shanghai Petrochemical Company.

\subsection{Catalyst preparation}

Four operating processes for the synthesis of ZSM-5 zeolites, including RPB premix - static crystallization, RPB premix - dynamic crystallization, STR premix - static crystallization, and STR premix - dynamic crystallization, are schematically showed in Fig. 1. 


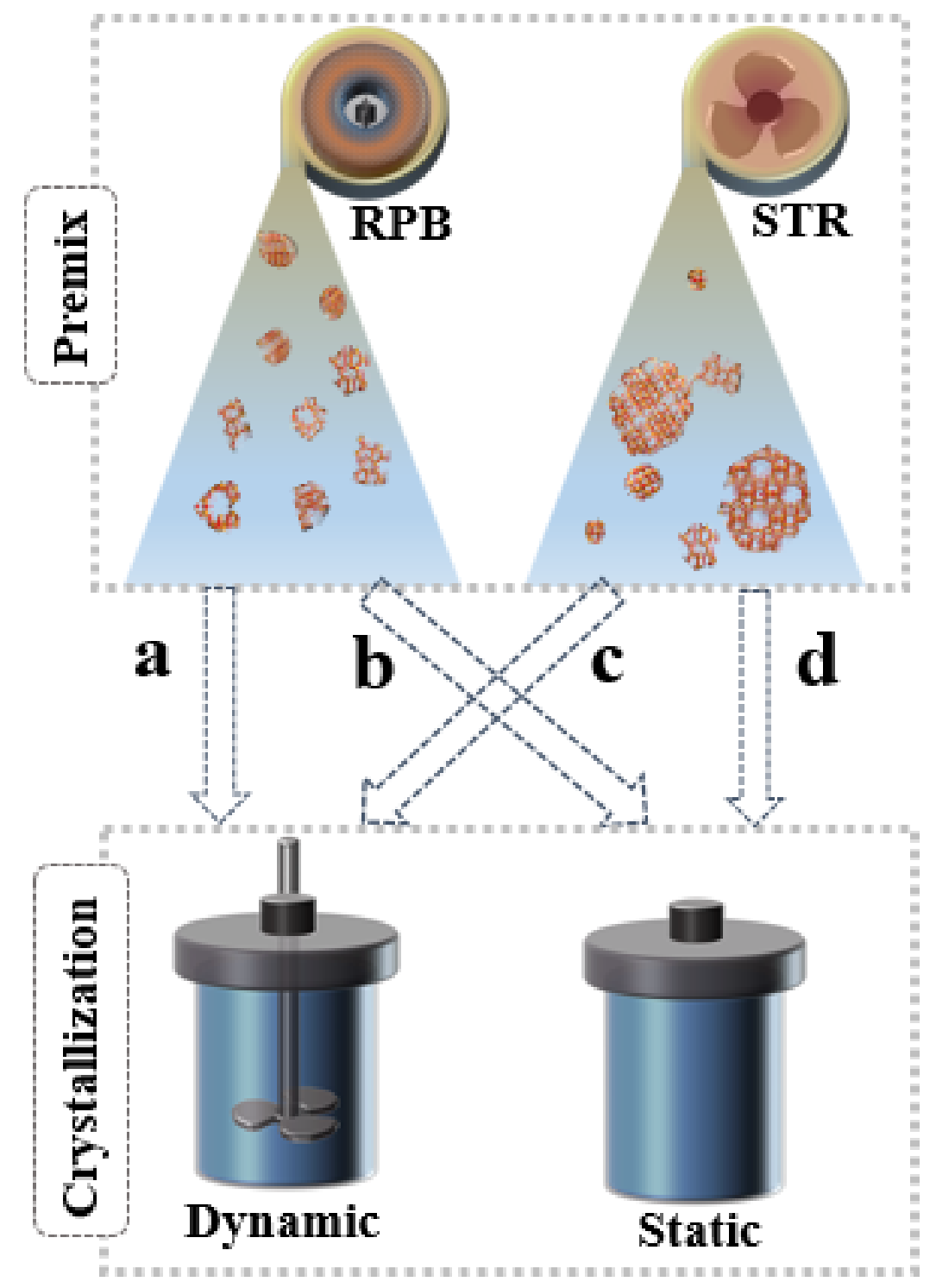

Fig. 1. Schematic diagram of four operating processes for synthesizing ZSM-5 zeolites: a) RPB premix static crystallization, b) RPB premix - dynamic crystallization, c) STR premix - static crystallization and d) STR premix - dynamic crystallization

To start a synthesis, a certain amount of chemicals (silica sol (40 wt\% aqueous solution), $\mathrm{Al}_{2}\left(\mathrm{SO}_{4}\right)_{3} \cdot 18 \mathrm{H}_{2} \mathrm{O}$, TPAOH (25 wt\% aqueous solution), $\mathrm{NaCl}, \mathrm{H}_{2} \mathrm{O}$ ) were measured following a molar ratio of $200 \mathrm{SiO}_{2}: \mathrm{Al}_{2} \mathrm{O}_{3}$ : 80TPAOH: $30 \mathrm{NaCl}$ : $4500 \mathrm{H}_{2} \mathrm{O}$. Two sources, including (A) silica source prepared by silica sol, and (B) aluminum source prepared by $\mathrm{Al}_{2}\left(\mathrm{SO}_{4}\right)_{3} \cdot 18 \mathrm{H}_{2} \mathrm{O}, \mathrm{NaCl}$, water and $\mathrm{TPAOH}$, were prepared respectively at room temperature under vigorous stirring for $0.5 \mathrm{~h}$ to obtain a homogeneous solution. In an RPB premixing process, the above two sources were pumped into RPB via two flow meters, respectively. And then the initial gel was cycled by a peristaltic pump for $30 \mathrm{~min}$, operating with a circulation rate of $540 \mathrm{~mL} \cdot \mathrm{min}^{-1}$ and a rotation speed of $1000 \mathrm{rpm}$. While in an STR premixing process, the silica source was slowly added dropwise into the aluminum source at a rotation speed of $1000 \mathrm{rpm}$ for $1 \mathrm{~h}$. The as-obtained gel was then poured into $100 \mathrm{~mL}$ Teflon-lined autoclave for traditional static crystallization and $500 \mathrm{~mL}$ STR for dynamic 
crystallization, respectively. In the hydrothermal crystallization process, static crystallization was carried out at 130 for $24 \mathrm{~h}$, and dynamic crystallization was at 130 for $16 \mathrm{~h}$ with a stirring speed of $1000 \mathrm{rpm}$ in the STR. After these processes, as-obtained samples were washed with deionized water and centrifuged at $6000 \mathrm{rpm}$ for $5 \mathrm{~min}$ with repeating four times, followed by drying at $110 \mathrm{degC}$ for $12 \mathrm{~h}$ and calcining at 550 $\operatorname{deg} \mathrm{C}$ for $3.5 \mathrm{~h}$ to remove the template. Finally, samples were converted to proton form by refluxing twice in $1.0 \mathrm{M} \mathrm{NH}_{4} \mathrm{NO}_{3}(5.0 \mathrm{~g}$ solid per $200 \mathrm{~mL}$ solution) for $4 \mathrm{~h}$, followed by drying at $110 \operatorname{degC}$ for $12 \mathrm{~h}$ and calcining at $550 \operatorname{deg} \mathrm{C}$ for $3.5 \mathrm{~h}$. The resulting samples are denoted as ZSM-5 samples.

\subsection{Nucleation/crystal growth mechanism of zeolite ZSM-5 studies}

During the premix and crystallization processes, small aliquots of the reaction solution were taken in different time for analysis to explore the effects of enhancing micromixing on the nucleation/crystal growth process of ZSM-5 zeolites. The aliquot was washed with deionized water and centrifuged at $6000 \mathrm{rpm}$ for 5 min until the $\mathrm{pH}$ was below 9 , followed by drying at room temperature. After drying, the aliquots were analyzed by FTIR and XRD to study the nucleation/crystal growth mechanism of ZSM-5 zeolites. These measurements were repeated three times.

\subsection{Characterization}

XRD patterns of the ZSM-5 zeolites and its reaction intermediates were recorded on an XRD-6000 diffractometer (Shimadzu Inc.) using $\mathrm{Cu} K$ a radiation $\left(40 \mathrm{kV}, 40 \mathrm{~mA}\right.$ ), in the $2 \vartheta$ range from $5^{\circ}$ to $90^{\circ}$, with a step size of $0.02^{\circ}$ and a counting time of $10 \mathrm{~s}$ per step. The elemental composition ( $\mathrm{Si} / \mathrm{Al}$ ratio) of the sample was determined by XRF spectrometer (Rigaku). Morphology and particle size of ZSM-5 zeolites were observed by scanning electron microscopy (SEM, Tescan). FTIR spectroscopic analyses were carried out with pressing potassium bromide troche (in a mass ratio of $1 / 100$ ) on a Nicolet 6700 spectrometer (Nicolet Instrument Co., USA) in the wavenumber range of 4000-400 $\mathrm{cm}^{-1}$. The textural properties of the sample were characterized on a Quantachrome surface area analyzer. The pore size distributions were calculated by Barrett-JoynerHalenda method from the desorption branch of the isotherm. The surface elemental composition ( $\mathrm{Si} / \mathrm{Al}$ ratio) was tested using X-ray photoelectron spectroscopy (XPS; Kratos AXIS SUPRA, Shimadzu) equipped with an $\mathrm{Al} K \alpha$ excitation source. $\mathrm{NH}_{3}$ temperature-programmed desorption (TPD) experiments were conducted on a chemisorption AutoChem II 2920 analyzer with a thermal conductivity detector (TCD) for analyzing surface acid properties. $100 \mathrm{mg}$ of the sample was pretreated under Helium at $550^{\circ} \mathrm{C}$ for $1 \mathrm{~h}$ and then saturated with a flow mixed with $10 \%$ ammonia and $90 \%$ He at $100{ }^{\circ} \mathrm{C}$ for $80 \mathrm{~min}$. Afterward, the sample was kept in He flow for 30 min to remove physically adsorbed ammonia, followed by heating to 600 ${ }^{\circ} \mathrm{C}$ at a rate of $10{ }^{\circ} \mathrm{C} / \mathrm{min}$ in $\mathrm{He}(30 \mathrm{~mL} / \mathrm{min})$. The amount of Brønsted and Lewis acid of the sample was measured by Pyridine-adsorbed FT-IR spectra using Nicolet Model 710 instrument. The sample was treated under vacuum at $350{ }^{\circ} \mathrm{C}$ for $1 \mathrm{~h}$ and then cooled to $150{ }^{\circ} \mathrm{C}$. After that, the sample was maintained in the pyridine vapor at $150{ }^{\circ} \mathrm{C}$ for $2 \mathrm{~h}$. Before analysis by FTIR, the test system was evacuated for another $1 \mathrm{~h}$ to remove physically adsorbed pyridine. The FT-IR spectra of the saturated sample were recorded from 40 to $350{ }^{\circ} \mathrm{C}$ under vacuum for $1 \mathrm{~h}$, respectively.

\subsection{Catalytic test}

The catalyzing C4-olefin cracking reaction was carried out to test the catalytic activities of ZSM-5 samples in a stainless catalytic reactor. C4-olefin was used as the reactant without further purification. The cracking of the C4-olefin test was carried out in a continuous flow fixed-bed system with a stainless steel tubular reactor $(\Phi 10 \mathrm{~mm} \times 530 \mathrm{~mm})$ equipped with a laboratory-scale piston pump for C4-olefin input. The reaction was conducted at $823 \mathrm{~K}$ under a total pressure of $0.1 \mathrm{MPa}$. Before the experiments, the catalyst was in situ

heated at a ramp rate of $5 \mathrm{~K} \mathrm{~min}^{-1}$ to the reaction temperature in $\mathrm{N}_{2}$ flow $\left(100 \mathrm{ml} \mathrm{min}^{-1}\right)$ and maintained at this temperature for $2 \mathrm{~h}$. The output products were analyzed online on an HP 6890 gas chromatograph equipped with a flame ionization detector (FID). 


\section{Results and discussion}

\subsection{Nucleation/crystal growth mechanism of ZSM-5 zeolites}

The nucleation/crystal growth mechanism is significant for the controllable synthesis of ZSM-5 zeolites. The characterization methods with high sensitivity to the amorphous matrix and crystalline species are necessary for the mechanism study [28]. FTIR spectroscopy is often employed to observe the short-range order structures of crystals, and IR vibrations of the structural units of zeolites are intense in the nucleation process [29]. XRD analysis is usually used to study the long-range order structures of crystals, which is beneficial to studying the growth process of zeolites [30]. Fig. 2 displays the FTIR spectra of solid aliquots drawn off the reaction mixture at $\mathrm{t}=0.5 \mathrm{~h}$ (after $\mathrm{RPB}$ premix) and $\mathrm{t}=1.5-8.5 \mathrm{~h}$ (under dynamic crystallization at 130 ).

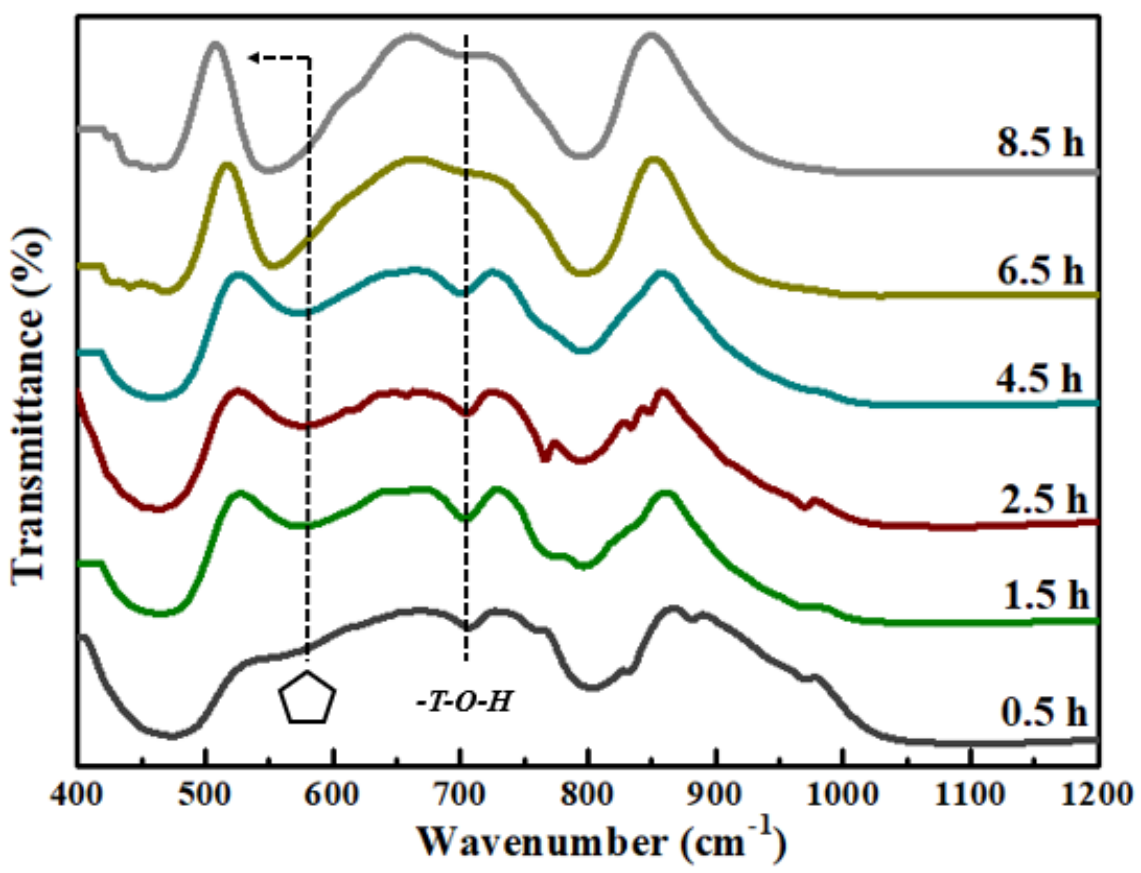

Fig. 2. FTIR spectra of the solid aliquots from a series of experiments at different intervals.

The aliquots prepared for 0.5-8.5 h show broad absorption bands in the range of 400-1200 $\mathrm{cm}^{-1}$, which are associated with amorphous sodium aluminosilicate gels [31]. Structure sensitive vibrations of aliquots with obvious change occurs near $530-560$ and $710 \mathrm{~cm}^{-1}$. The band at $530-560 \mathrm{~cm}^{-1}$ is indicative for D5 ring units, which is typical of dominating secondary structural units in the MFI-type structure [29,32,33]. This weak broad band appears after the $0.5 \mathrm{~h}$ RPB premix process. After $1.5 \mathrm{~h}$ dynamic hydrothermal treatment, this band becomes sharper with the crystallization time prolonged, indicating the occurrence of the zeolite nucleus [31, 34]. Moreover, the gradual redshift of this peak position indicates that the $\mathrm{SiO}_{4}$ tetrahedra in the D5 ring unit are substituted continuously by $\mathrm{AlO}_{4}$ tetrahedra [35,36], which leads to the formation of Si-OH-Al, corresponding to Brønsted acid sites [37]. The band at $710 \mathrm{~cm}^{-1}$ is indicative for T-OH bending vibrations $(\mathrm{T}=\mathrm{Si} / \mathrm{Al})$, which represents the occurrence of hydrolysis reaction between $\mathrm{Si}^{4+}$ and $\mathrm{Al}^{3+}[28]$ and the formation of $\mathrm{TO}_{4}$ tetrahedral assembled into zeolite skeleton [38]. This band has occurred at 0.5 $\mathrm{h}$, indicating the hydrolysis reaction has taken place in the RPB premix process at room temperature. The gradual disappearance of the $710 \mathrm{~cm}^{-1}$ peak is consistent with an increase in the intensity of the $530-560 \mathrm{~cm}^{-1}$ band, suggesting that the amount of framework atoms connected by oxygen bridges increases constantly. 
This indicates the amorphous gels have transformed gradually into zeolite crystals [39].

Fig. 3. XRD patterns of solid aliquots obtained by (A) RPB and (B) STR premix at different intervals.

Fig. 3A shows the XRD patterns of solid aliquots obtained by 30 min RPB premix and dynamic crystallization at different intervals. X-ray detection limit has no impact on the analysis result [28-30]. The first crystalline phase with the crystallinity of $30 \%$ was detected at $5.5 \mathrm{~h}$, and the crystallinity is $50 \%$ after $6.5 \mathrm{~h}$, indicating that the crystallization of the amorphous gel into long-range order zeolite skeleton has occurred at $5.5 \mathrm{~h}$ of hydrothermal treatment.

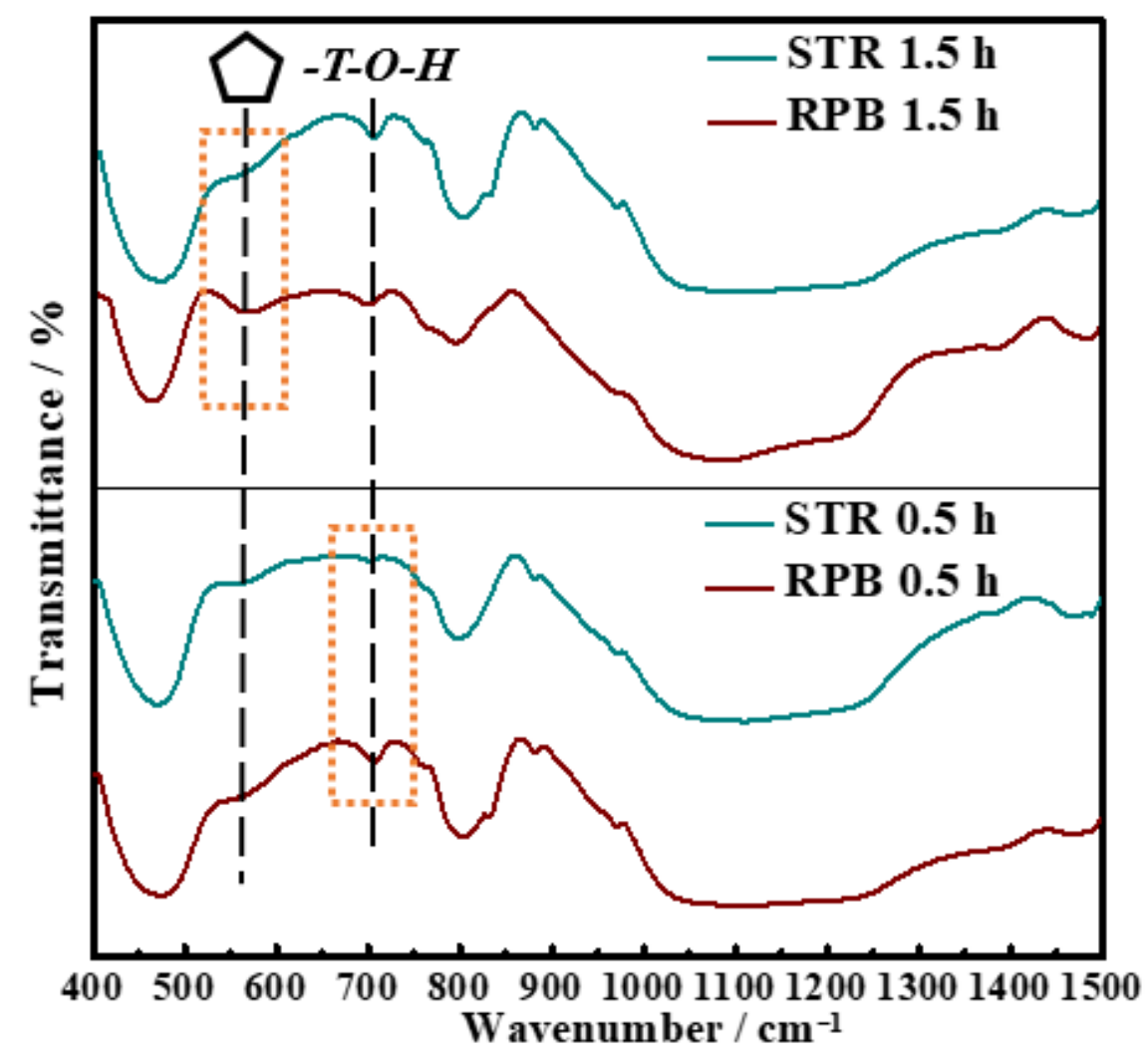

Fig. 4. FTIR spectra of the solid aliquots obtained by (A) RPB and (B) STR premix at different intervals.

To investigate the effect of enhancing micromixing in the zeolite synthetic pathway on the nucleation/crystal growth process, the gel was pretreated by STR for $30 \mathrm{~min}$ as a comparison. As shown in Fig. 4, the D5 ring and T-OH structural units' band pretreated by RPB usually occurred earlier than those by STR. This indicates the enhancement of micromixing during the premix process accelerated the nucleation process of zeolites. XRD results (Fig. 3) further confirm that the crystallization process has been speeded up via RPB premix, accompanied by the growth of the nucleus [29]. The reason is that the water phase (aluminum source), containing a large amount of $\mathrm{OH}^{-}$and $\mathrm{TPA}^{+}$, was mixed thoroughly with the gel phase (silica source) by intensifying micromixing. The water phase provides a high $\mathrm{pH}$ environment for the hydrolysis of aluminosilicate and abundant structure-directing agents $\left(\mathrm{TPA}^{+}\right)$for assembly of structural units [40,41]. The better micromixing of two phases in the RPB facilitates the faster polycondensation of structural units, resulting in the acceleration of nucleation and crystal growth of zeolites. 


\subsection{Characterization of the ZSM-5 samples}

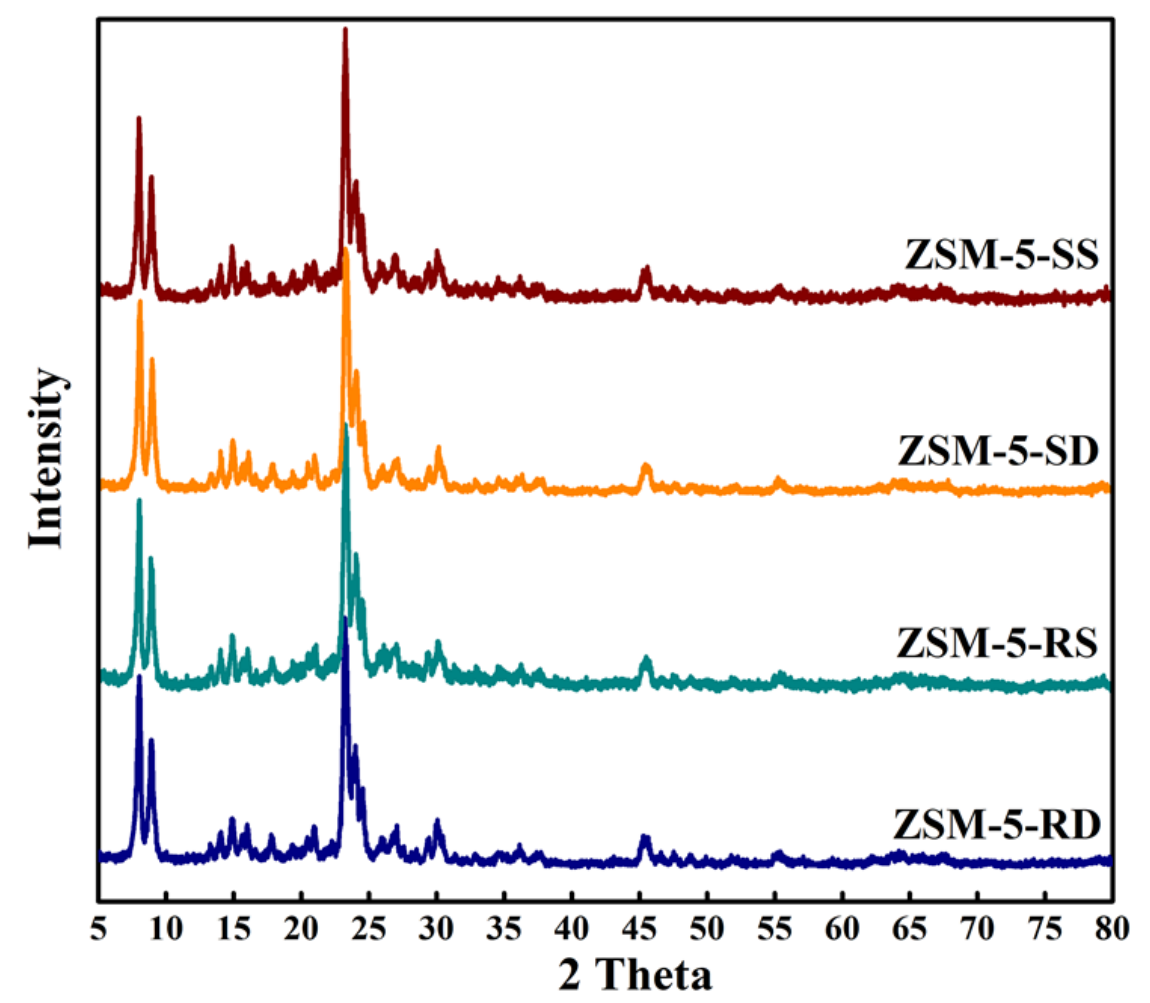

Fig. 5. XRD patterns of four ZSM-5 samples obtained by different operating processes.

Fig. 5 presents XRD patterns of ZSM-5 samples obtained by RPB premix - static crystallization (ZSM-5RS), RPB premix - dynamic crystallization (ZSM-5-RD), STR premix - static crystallization (ZSM-5-SS) and STR premix - dynamic crystallization (ZSM-5-SD). All the obtained samples are assigned to highly crystallized ZSM-5 corresponding to the typical MFI topology. Independently of micromixing intensity, the crystal form and growth face of ZSM-5 samples have no obvious differences in the four operating routes mentioned above, indicating the crystal form and growth face main determined by reaction temperature rather than micromixing effect.

The morphological properties of four ZSM-5 samples are shown in Fig. 6. All ZSM-5 samples exhibited spherical morphologies but the particle size distributions were not consistent. The ZSM-5 samples pretreated by RPB premix displayed narrower particle size distributions and smaller average particle sizes compared with those by STR premix, indicating that the uniform distribution of structural units and $\mathrm{TPA}^{+}$could facilitate the increase of nucleation sites. The number of structural units and $\mathrm{TPA}^{+}$are certain in the whole reaction system, the more crystal nucleus assembled by structural units, the fewer remaining structural units for crystal growth, resulting in the decrease of final particle sizes. Moreover, under the same premixing process, dynamic crystallization results in narrower particle size distributions of ZSM-5 samples with less crystallization time because of the uniform growth of zeolites in a relatively homogeneous crystallization environment. ZSM-5-RD showed the narrowest size distribution ranging from 160 to $400 \mathrm{~nm}$ with an average size of $290 \mathrm{~nm}$. 

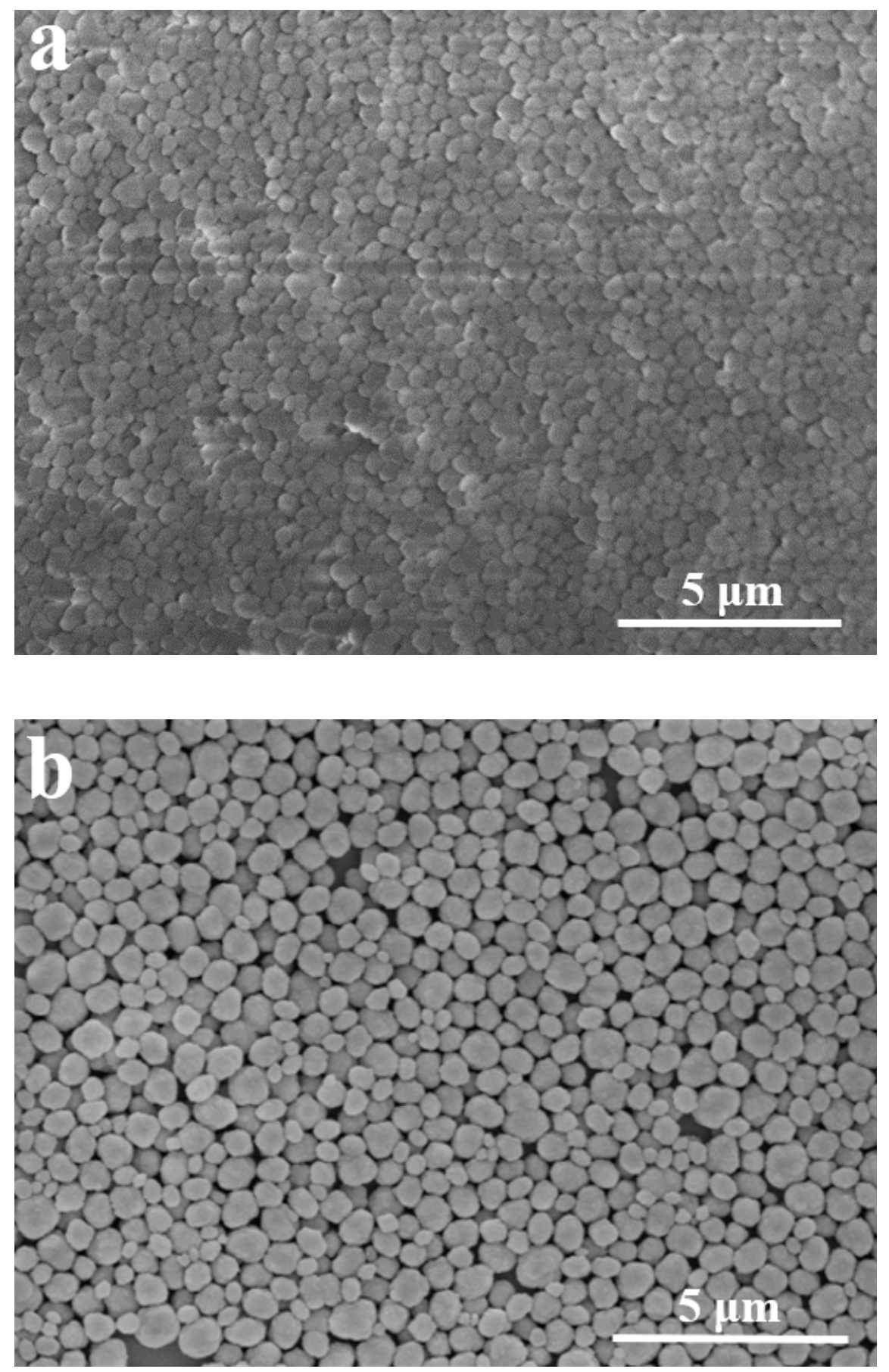

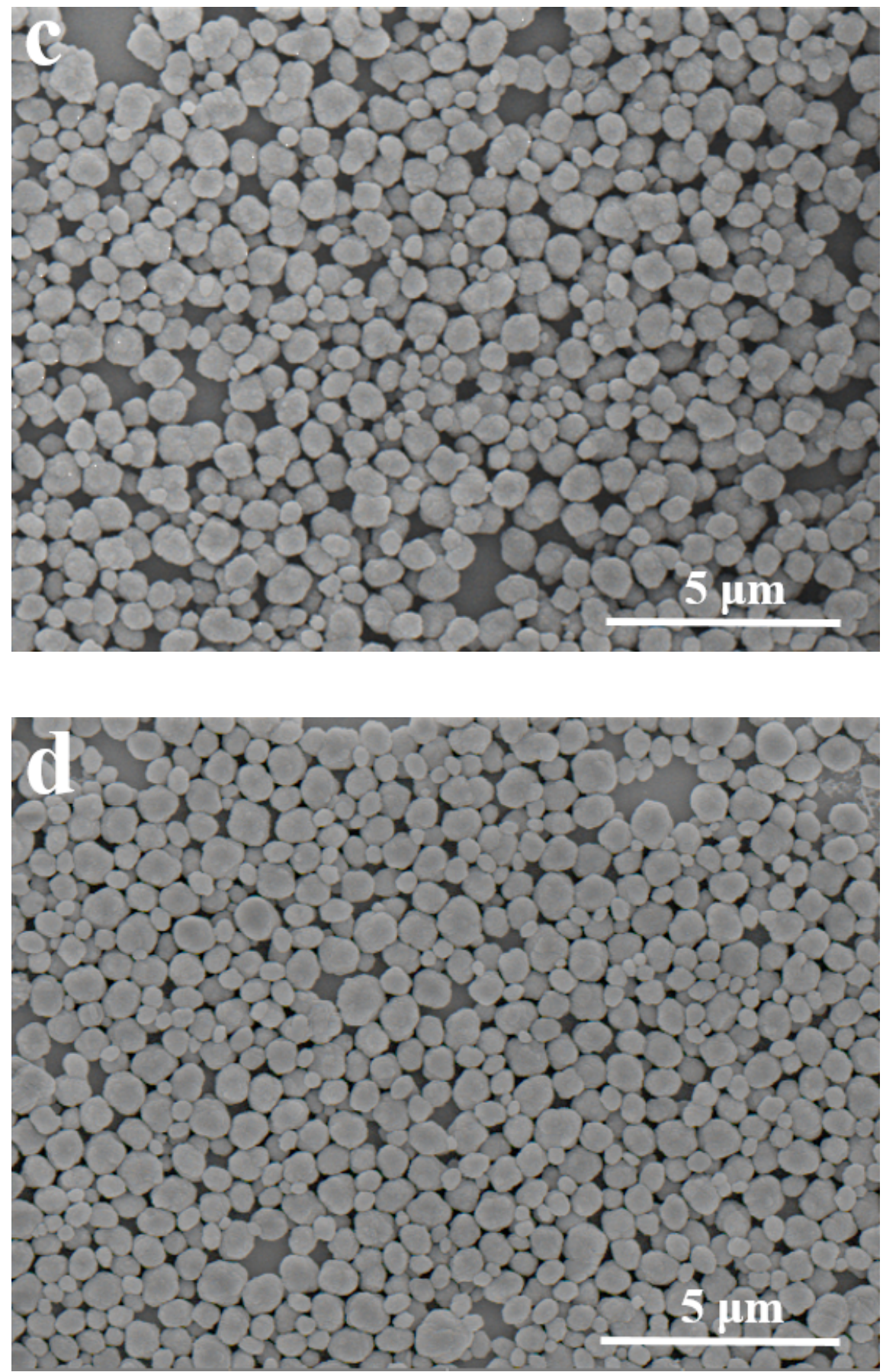


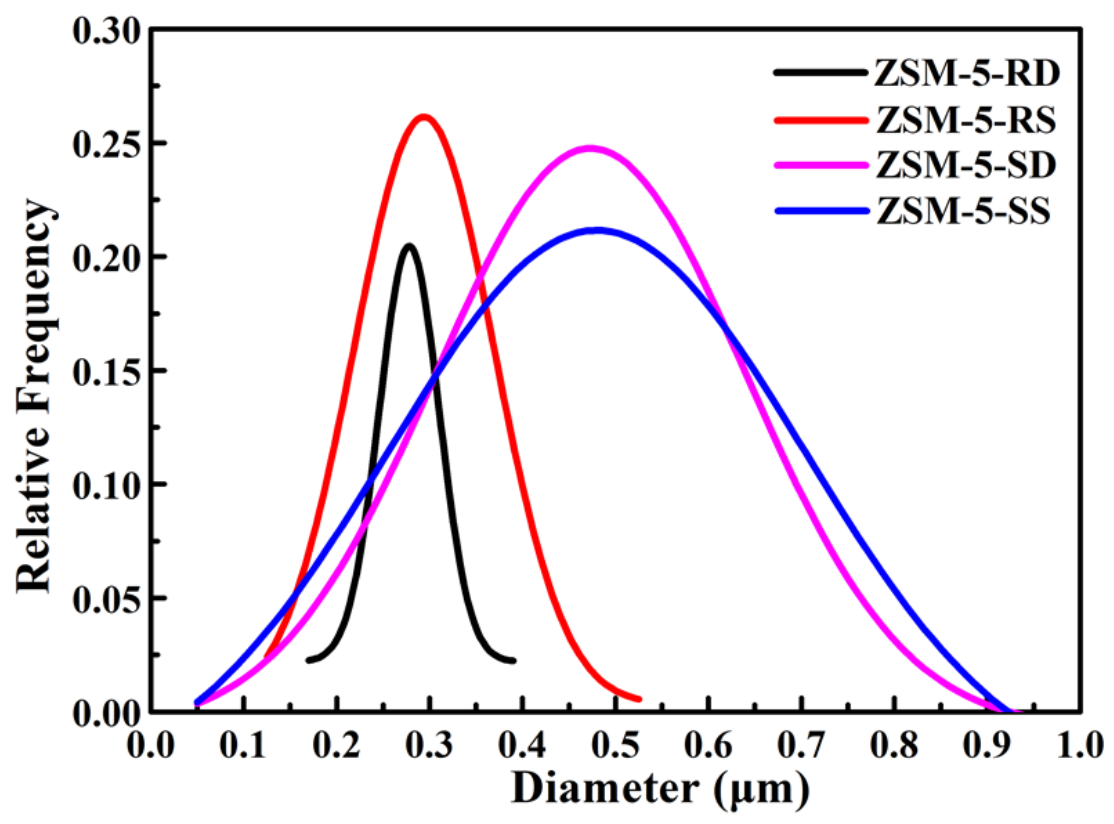

Fig. 6. SEM images and particle size distributions of (a) ZSM-5-RD, (b) ZSM-5-RS, (c) ZSM-5-SD, (d) ZSM-5-SS.

The textural properties of four ZSM-5 samples are summarized in Table 1. The $\mathrm{N}_{2}$ adsorption-desorption isotherms of ZSM-5 samples obtained via RPB premix differ from those by STR (Fig. 7). Besides the steep uptake below $P / P_{0}=0.02$ in the isotherms of all samples (indicating uniform microporous in ZSM- 5 zeolites), there is an H4 hysteresis loop of the ZSM- 5 samples obtained via RPB premix when $P / P_{0}$ is 0.45 , which indicates the presence of slit-shaped mesoporous structures [42]. The textural properties in Table 1 reveal that the surface areas and pore volumes of ZSM-5 samples obtained via RPB premix are higher than those via STR premix. And the mesoporous characters are generated accompanied by the decrease of microporous structures [43]. 


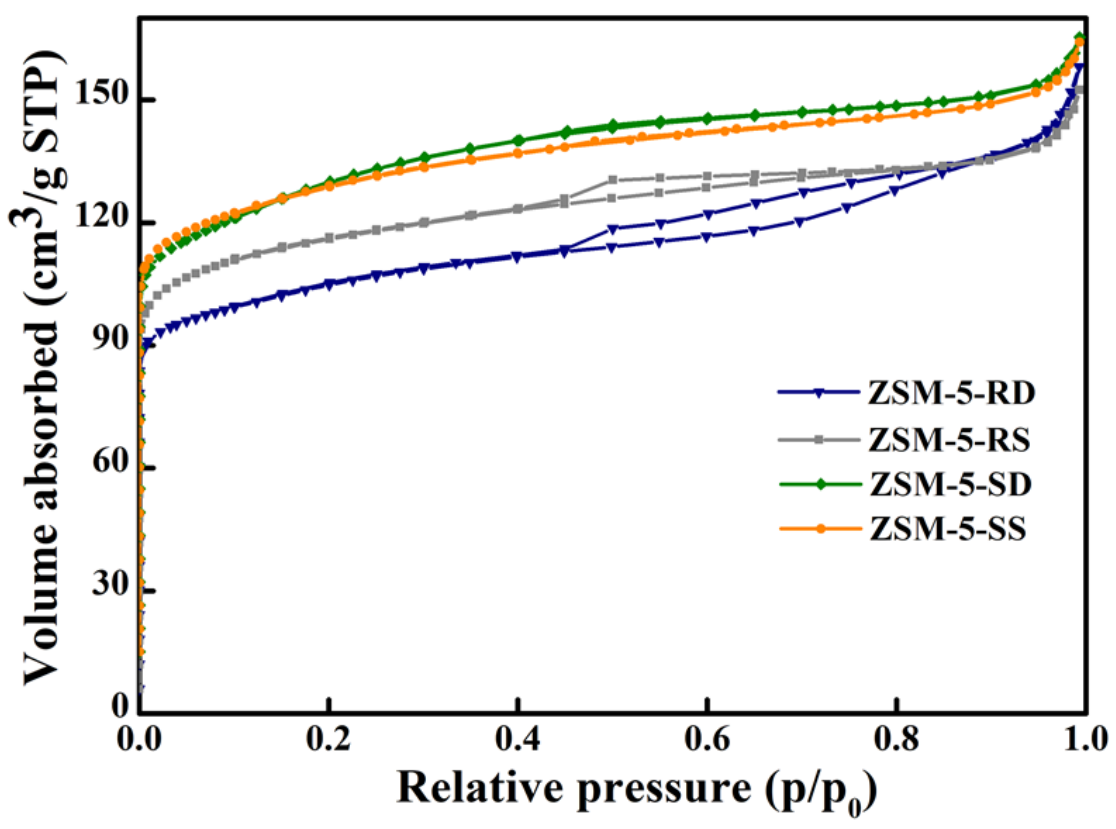

Fig. $7 \mathrm{~N}_{2}$ adsorption and desorption isotherms of four ZSM-5 samples obtained by different operating processes.

Table 1. Textural properties of four ZSM-5 samples obtained by different operating processes.

\begin{tabular}{llll}
\hline sample & $S_{\mathrm{BET}} / \mathrm{m}^{2} \mathrm{~g}^{-1}$ & $V_{\mathrm{t}} / \mathrm{cm}^{3} \mathrm{~g}^{-1}$ & $V_{\text {mic }} / \mathrm{cm}^{3} \mathrm{~g}^{-1}$ \\
\hline ZSM-5-RD & 520.9 & 0.26 & 0.13 \\
ZSM-5-RS & 517.3 & 0.25 & 0.15 \\
ZSM-5-SD & 463.3 & 0.23 & 0.21 \\
ZSM-5-SS & 461.2 & 0.23 & 0.22 \\
\hline
\end{tabular}

Fig. 8 shows the pore size distribution curves calculated by Barrett-Joyner-Halenda (BJH) method. The hierarchical structure of the ZSM-5 samples obtained via RPB premix can be observed. Furthermore, the average pore size of ZSM5-RD is larger than that of ZSM5-RS, and an increase of cumulative pore volume in the diameter range of 4.5-8.0 $\mathrm{nm}$ is presented for the former sample. In contrast, ZSM5-SS and ZSM5-SD exhibit fewer mesopores than ZSM5-RS and ZSM5-RD, indicating that the textural properties of ZSM-5 samples are greatly affected by the micromixing intensity in the nucleation process. 


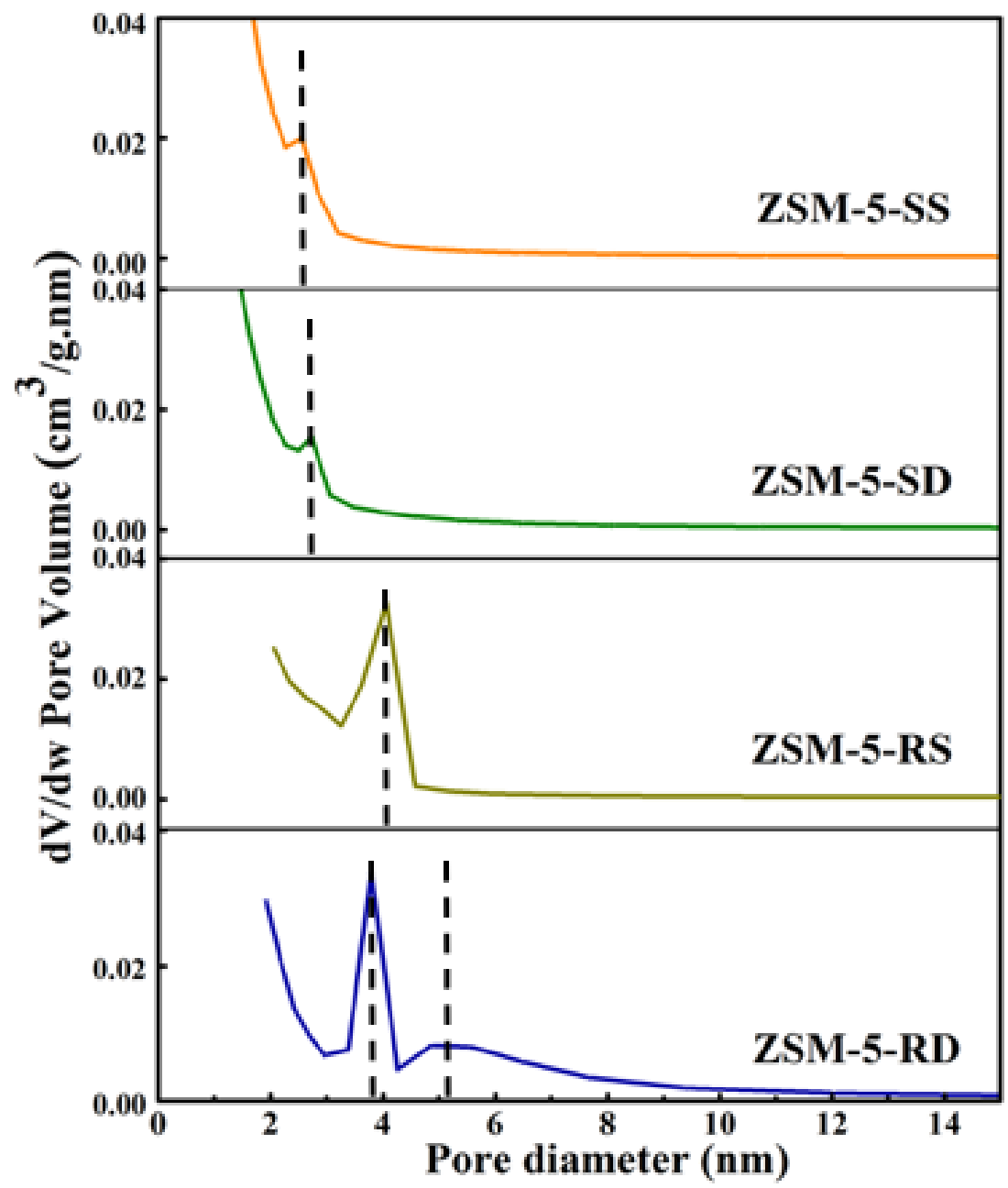

Fig. 8. BJH pore size distributions of four ZSM-5 samples obtained by different operating processes.

Surface- and bulk- chemical compositions of ZSM-5 were measured by XPS and XRF respectively, which are displayed in Table 2. Both on surfaces and in bulk phases, the Si/Al ratios of ZSM-5 samples obtained via RPB premix are much lower than those via STR premix, which indicates that the concentration of $\mathrm{Al}$ sites is correlated with the micromixing intensity in the zeolite nucleation period. The significant increase in the $\mathrm{Al}$ content of ZSM-RS/RD indicates that enhancing micromixing by RPB premix plays a quite important role in the formation of $\mathrm{Al}$ sites in the zeolite in the growth process. Besides, the $\mathrm{Al}$ contents on surfaces of ZSM-5 samples are higher than those in bulk phases, which is correspond with the zeolite SAPO-34 reported by Xing et al. [44]. Moreover, with the same premixing process, the products prepared by dynamic crystallization could impel more Al into the bulk of zeolite ZSM-5 compared with those obtained by static crystallization, which indicates that intensifying micromixing by dynamic crystallization improves the driving force of substitution reaction of $\mathrm{Al}$.

Table 2. Chemical composition of ZSM-5 samples analyzed by XRF and XPS.

\begin{tabular}{llll}
\hline Sample & $(\mathrm{Si} / \mathrm{Al})_{\text {gel }}$ & $(\mathrm{Si} / \mathrm{Al})_{\mathrm{XRF}}$ & $(\mathrm{Si} / \mathrm{Al})_{\mathrm{XPS}}$ \\
\hline ZSM-5-RS & 200 & 142 & 138 \\
ZSM-5-RD & 200 & 138 & 134
\end{tabular}




\begin{tabular}{llll}
\hline Sample & $(\mathrm{Si} / \mathrm{Al})_{\text {gel }}$ & $(\mathrm{Si} / \mathrm{Al})_{\mathrm{XRF}}$ & $(\mathrm{Si} / \mathrm{Al})_{\mathrm{XPS}}$ \\
\hline ZSM-5-SS & 200 & 178 & 167 \\
ZSM-5-SD & 200 & 167 & 164 \\
\hline
\end{tabular}

The ZSM-5 samples prepared by different synthesis routes have different acid properties. The surface acid properties of four ZSM-5 samples were investigated by $\mathrm{NH}_{3}$-TPD and pyridine FT-IR experiments. As shown in Fig. 9, all ZSM-5 samples have two $\mathrm{NH}_{3}$ desorption peaks at 186-189 and 387-405, which correspond to weak acid sites and strong surface acid sites, respectively [44]. The acid amount and acid strength of samples are reflected by peak area and peak position of the TPD profile, respectively [45]. As shown in Table 3, acid amount and strong surface acid strength of ZSM5-RS and ZSM5-RD increase significantly compared with ZSM5-SS and ZSM5-SD. Moreover, the desorption temperature of ammonia from the strong acid sites shifted to higher temperatures as inducing RPB in the premix process, which indicates the increase of $\mathrm{Al}$ content in extra-framework positions [34]. In comparison with ZSM5-SS, the acid amount and acid strength of ZSM5-SD have a slight growth. A possible reason is that the enhancement of micromixing in the STR affects the acid properties of zeolites in the crystallization process.

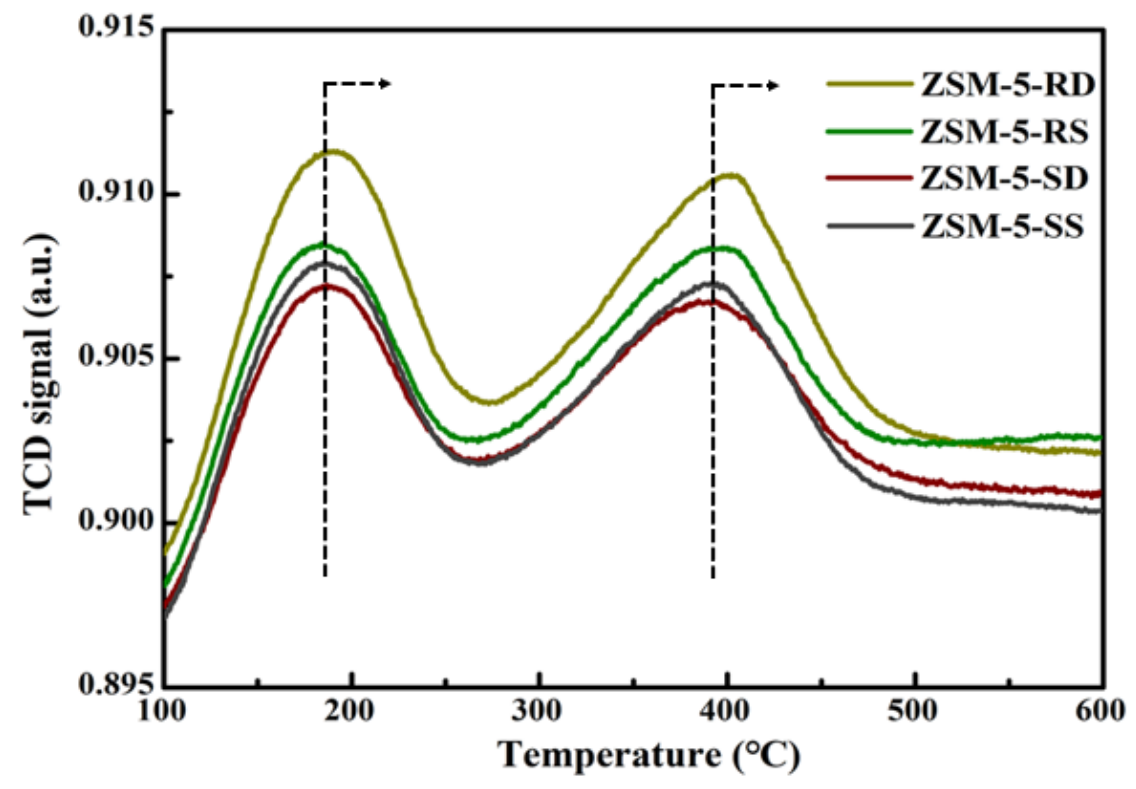

Fig. 9. $\mathrm{NH}_{3}$-TPD profiles of four ZSM-5 samples obtained by different operating processes.

Table 3. Quantification of acid sites according to $\mathrm{NH}_{3}$-TPD profiles.

\begin{tabular}{lllll}
\hline sample & peak 1 & peak 1 & peak 2 & peak 2 \\
\hline & amount $^{a}$ & temp $\left({ }^{\circ} \mathrm{C}\right)$ & amount & temp $\left({ }^{\circ} \mathrm{C}\right)$ \\
ZSM-5-RD & 0.33 & 190 & 0.46 & 404 \\
ZSM-5-RS & 0.33 & 187 & 0.41 & 402 \\
ZSM-5-SD & 0.31 & 185 & 0.38 & 392 \\
ZSM-5-SS & 0.28 & 185 & 0.36 & 390 \\
\hline
\end{tabular}

${ }^{a}$ The unit of the acid amount is mmol $\mathrm{g}^{-1}$. 
The pyridine FT-IR results are shown in Fig. 10, both Brønsted (B) and Lewis (L) acid sites are present on all ZSM-5 samples' surface, corresponding to the stretching bands at around 1540 and $1450 \mathrm{~cm}^{-1}$, respectively $[9,46,47]$. The peaks near $1490 \mathrm{~cm}^{-1}$ can be attributed to the pyridine species interacting with B and $\mathrm{L}$ acid sites [48]. The ZSM-5 samples prepared via enhancing micromixing no matter in the premixing or crystallization process exhibit a larger amount of B and L acid sites at 200 (Table 4). For all ZSM-5 samples, compared to B acid sites, the amount of $\mathrm{L}$ acid sites decreases obviously with the increasing temperature (Table S1), indicating that the strength of $\mathrm{L}$ acid sites is weaker than B acid sites [48].

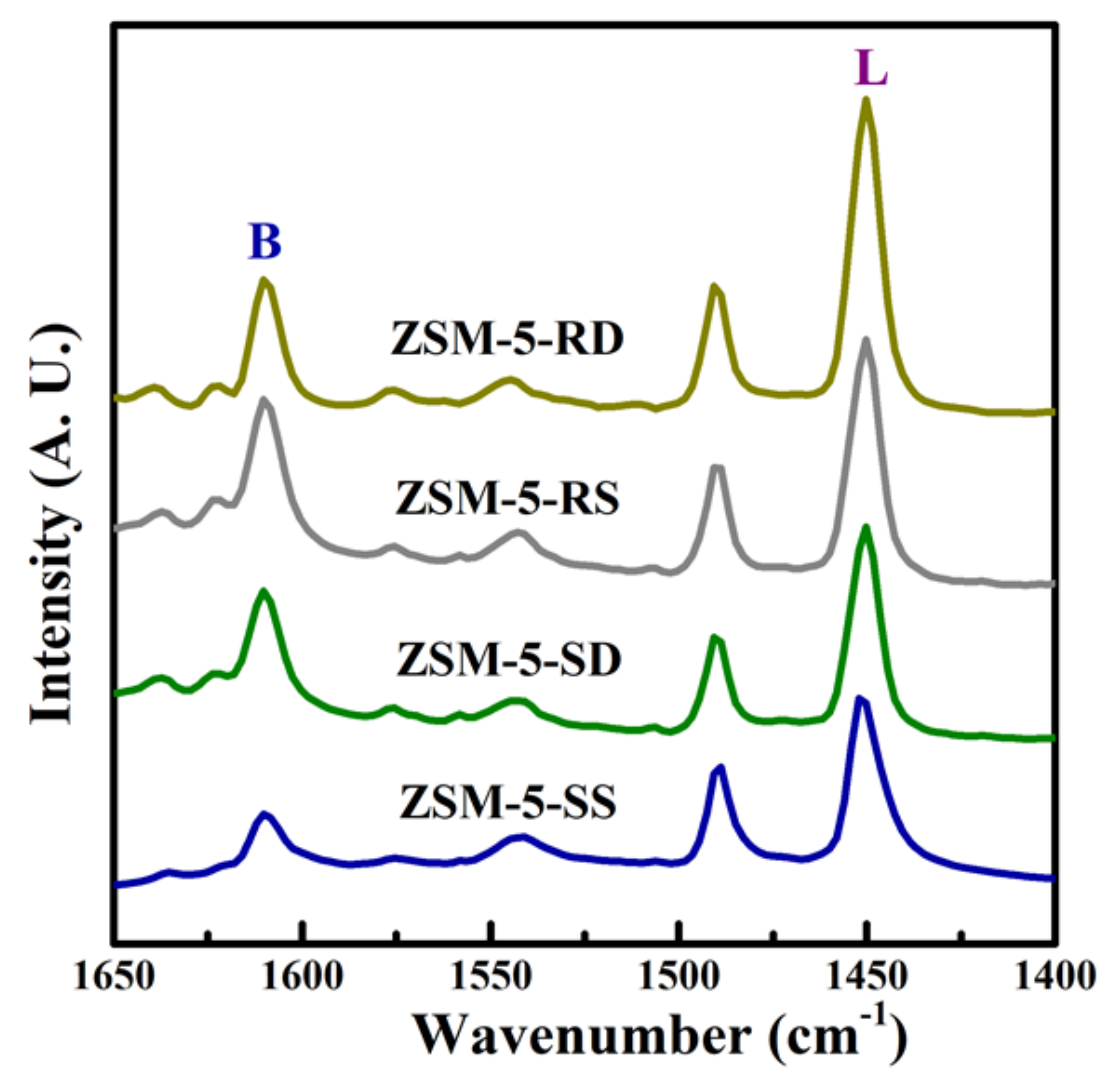

Fig. 10. FT-IR spectra after the adsorption of pyridine followed with desorption of ZSM-5 samples obtained by different operating processes.

Table 4. Quantification of acid sites according to the FT-IR experiments.

\begin{tabular}{lll}
\hline sample & $\mathrm{B}^{a}\left(\mu \mathrm{mol} \mathrm{g}^{-1}\right)$ & $\mathrm{L}^{b}\left(\mu \mathrm{mol} \mathrm{g}{ }^{-1}\right)$ \\
\hline ZSM-5-RD & 24.52 & 169.11 \\
ZSM-5-RS & 19.52 & 136.97 \\
ZSM-5-SD & 16.29 & 114.60 \\
ZSM-5-SS & 9.71 & 71.75 \\
\hline
\end{tabular}

${ }^{a}$ Brønsted and ${ }^{b}$ Lewis acid amount at 200 . 


\subsection{Catalytic performance}

The cracking reaction of C4-olefin (OCC) to propylene in industries is an important application of ZSM-5 zeolites, and the conversion of C4-olefin and yield of propylene mostly depend on zeolites' acidity, pore structure and catalytic stability [49]. In this study, we investigated the catalytic performance of four ZSM5 samples for the OCC reaction. The conversion of C4-olefin and yield of propylene obtained under the catalysis of different ZSM-5 samples are shown in Fig. 11. At first, the C4-olefin's conversion and yield of propylene under the catalysis by the four ZSM-5 samples had no obvious difference. However, the conversions of C4-olefin catalyzed by the ZSM-5-SD and ZSM-5-SS decreased faster than those by ZSM-5-RD and ZSM5-RS after $16 \mathrm{~h}$. And the conversions of C4-olefin by the ZSM-5-RD, ZSM-5-RS, ZSM-5-SD, and ZSM-5-SS were $65 \% 62 \%, 53 \%$ and $53 \%$ at $44 \mathrm{~h}$, respectively. Besides, the yield of propylene catalyzed by ZSM-5-RD and ZSM-5-RS were higher markedly than those catalyzed by ZSM-5-SD and ZSM-5-SS after $30 \mathrm{~h}$. This indicates that ZSM-5 samples prepared by RPB premix possess more active sites with weak Lewis acidity and medium-strong Bronsted acidity, less transfer limitation in micropore, and more excellent catalytic stability than those by STR premix.

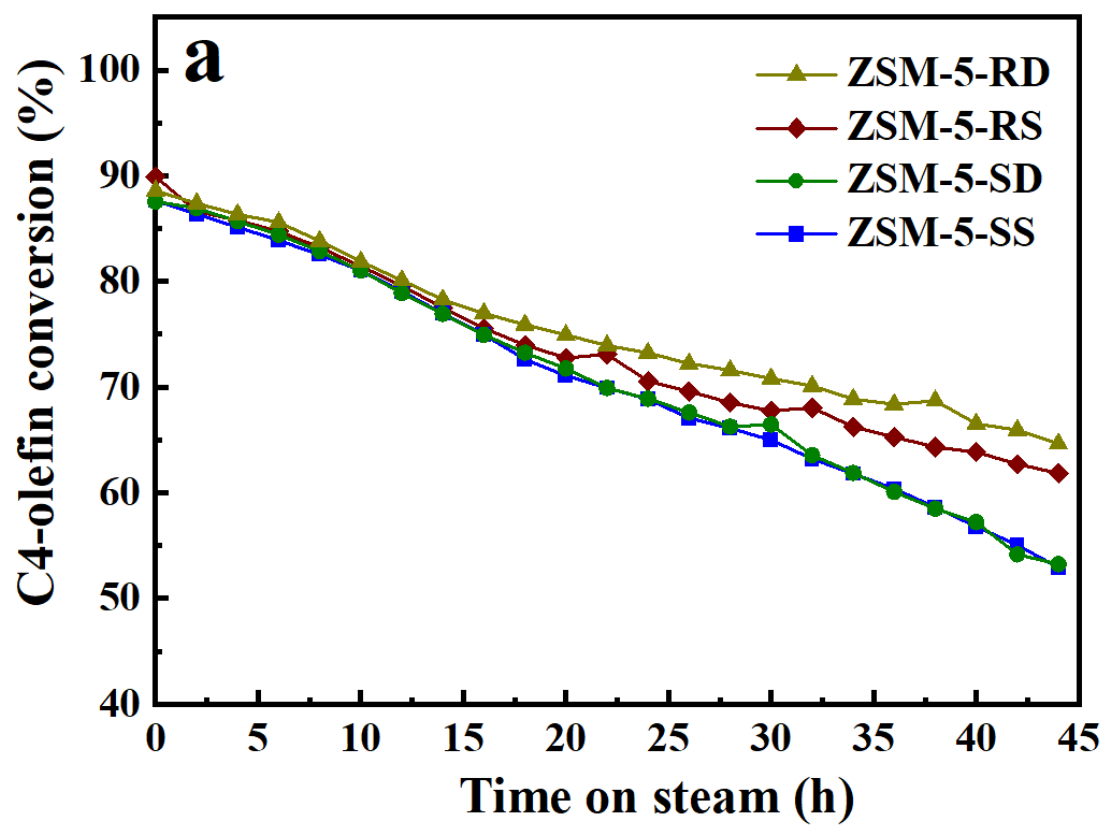




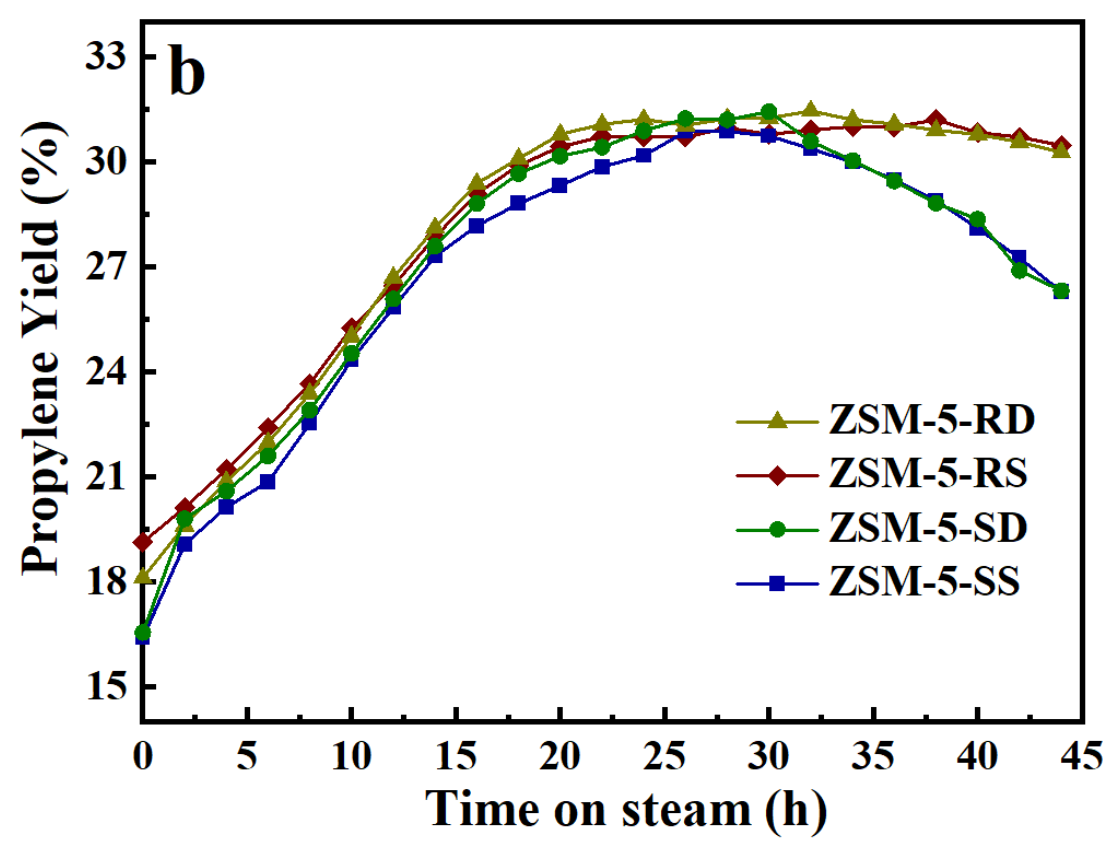

Fig. 11. (a) C4-olefin conversion and (b) propylene yield of four ZSM-5 samples.

\section{Conclusions}

In conclusion, this work presented a novel route for the synthesis of ZSM- 5 zeolites by using RPB for enhancing micromixing of high viscosity reaction system in the premix process. The as-prepared ZSM-5 zeolites by RPB premix exhibited hierarchical structure, smaller average particle size, more uniform particle size distributions, larger specific surface areas, more Brønsted and Lewis acid sites, and higher catalytic stability compared with those prepared by STR premix. Moreover, enhancing micromixing by RPB could facilitate the formation of $\mathrm{Al}$ sites and shorten the crystallization time. Also, the mechanisms of the nucleation/crystal growth process of zeolites under different micromixing intensity were studied. While adopting the prepared zeolites for catalyzing C4-olefin cracking reaction, zeolites prepared via RPB premix exhibited the remarkably higher conversion of C4-olefin and yield of propylene. Generally, the RPB premix synthetic routes speeded up the crystallization rate of zeolites and improved zeolites' catalytic performance with the advantages of convenient processing, cost-effectiveness, easy industrial scale-up.

\section{References}

1. Ai S, Zheng MY, Jiang Y, Yang XF, Li XS, Pang JF, Sebastian J, Li WZ, Wang AQ, Wang XD, Zhang T. Selective removal of 1,2-propanediol and 1,2-butanediol from bio-ethylene glycol by catalytic reaction. AIChE Journal. 2017; 63: 4032-4042.

2. Tian YJ, Liu H, Wang L, Zhang XW, Liu GZ. Controllable fabrication and catalytic performance of nanosheet HZSM-5 films by vertical secondary growth. AIChE Journal. 2018; 64: 1923-1927.

3. Corma A. From microporous to mesoporous molecular sieve materials and their use in catalysis. Chemical Reviews. 1997; 97: 2373-2420.

4. Quan YH, Li SY, Wang S, Li ZK, Dong M, Qin ZF, Chen G, Wei ZH, Fan WB, Wang JG. Synthesis of chainlike ZSM-5 zeolites: determination of synthesis parameters, mechanism of chainlike morphology 
formation, and their performance in selective adsorption of xylene isomers. ACS Applied Materials \& Interfaces. 2017; 9: 14899-14910.

5. Gao P, Xu GD, Wang C, Wang Q, Zhao YX, Zhang YH, Feng ND, Zhao XL, Li JL, Deng F. A mechanistic study of methanol-to-aromatics reaction over Ga-modified ZSM-5 zeolites: understanding the dehydrogenation process. ACS Catalysis. 2018; 8: 9809-9820.

6. Liang TY, Chen JL, Qin ZF, Li JF, Wang PF, Wang S, Wang GF, Dong M, Fan WB, Wang JG. Conversion of methanol to olefins over H-ZSM-5 zeolite: reaction pathway is related to the framework aluminum siting. ACS Catalysis. 2016; 6: 7311-7325.

7. Martinez C, Corma A. Inorganic molecular sieves: Preparation, modification and industrial application in catalytic processes. Coordination Chemistry Reviews. 2011; 255: 1558-1580.

8. Subhan F, Aslam S, Yan ZF, Liu Z, Etim UJ, Wadood A, Ullah R. Confinement of mesopores within ZSM-5 and functionalization with Ni NPs for deep desulfurization. Chemical Engineering Journal. 2018; 354: 706-715.

9. Jang HG, Min HK, Lee JK, Hong SB, Seo G. SAPO-34 and ZSM-5 nanocrystals' size effects on their catalysis of methanol-to-olefin reactions. Applied Catalysis A: General. 2012; 437-438: 120-130.

10. Zholobenko VL, Kustov LM, Kazansky VB, Loeffler E, Lohser U, Peuker Ch, Oehlmann G. On the possible nature of sites responsible for the enhancement of cracking activity of HZSM-5 zeolites dealuminated under mild steaming conditions. Zeolite. 1990; 10: 304-306.

11. Hong Y, Gruver V, Fripiat JJ. Pentane Conversion on Dealuminated H-Y and HZSM-5. Journal of Catalysis. 1996; 161: 766-775.

12. Niwa M, Katada N, Murakami Y. Generation of acid sites by $\mathrm{SiO}_{2}$ deposition on groups IVB metal oxides. Journal of Catalysis. 1992; 134: 340-348.

13. Ghosh AK, Kydd RA. Acidity and activity of fluorinated mordenites. Journal of Catalysis. 1987; 103: 399-406.

14. Zhao TT, Li FW, Yu HC, Ding SL, Li ZX, Huang XY, Li X, Wei XH, Wang ZL, Lin HF. Synthesis of mesoporous ZSM-5 zeolites and catalytic cracking of ethanol and oleic acid into light olefins. Applied Catalysis A: General. 2019; 575: 101-110..

15. Xu DD, Abdelrahman O, Ahn SH, Guefrachi Y, Kuznetsov A, Ren LM, Hwang SJ, Khaleel M, Hassan SA, Liu DX, Hong SB, Dauenhauer P. Tsapatsis M. A quantitative study of the structure-activity relationship in hierarchical zeolites using liquid-phase reactions. AIChE Journal. 2018; 65: 1067-1075.

16. Kim S, Shah J, Pinnavaia T. Colloid-imprinted carbons as templates for the nanocasting synthesis of mesoporous ZSM-5 zeolite. Chemistry of Materials. 2003; 15: 1664-1668.

17. Narayanan S, Vijaya JJ, Sivasanker S, Kennedy LJ, Jesudoss SK. Structural, morphological and catalytic investigations on hierarchical zeolite ZSM-5 hexagonal cubes by surfactant assisted hydrothermal method. Powder Technology. 2015; 274: 338-348.

18. Dong A, Wang Y, Tang Y, Zhang Y, Ren N, Gao Z. Mechanically stable zeolite monoliths with three-dimensional ordered macropores by the transformation of mesoporous silica spheres. Advanced Materials. 2002; 14: 1506-1510.

19. Xu R, Pang W, Yu J, Huo Q, Chen J. Chemistry of Zeolite and Related Porous Materials. Singapore: Wiley-VCH., 2007.

20. Askari S, Alipour SM, Halladj R, Hossein DAFM. Effects of ultrasound on the synthesis of zeolites: a review. Journal of Porous Materials. 2013; 20: 285-302.

21. Yin X, Sun Q, Wang D, Routh AF, Le Y, Wang JX, Chen JF. High-gravity-assisted synthesis of aqueous nanodispersions of organic fluorescent dyes for counterfeit labeling. AIChE Journal. 2019; 65.

22. Sun Q, Chen B, Wu X, Wang M. Zhang C, Zheng XF, Wang JX, Chen JF. Preparation of transparent suspension of lamellar magnesium hydroxide nanocrystals using a high-gravity reactive precipitation combined with surface modification. Industrial \& Engineering Chemistry Research. 2015; 54: 666-671.

23. Zheng XH, Chu GW, Kong DJ, Luo Y, Zhang JP, Zou HK, Zhang LL, Chen JF. Mass transfer intensification in a rotating packed bed with surface-modified nickel foam packing. Chemical Engineering Journal. 2016; 285: 236-242.

24. Chen JF, Wang YH, Guo F, Wang XM, Zheng C. Synthesis of nanoparticles with novel technology: 
high-gravity reactive precipitation. Industrial \& Engineering Chemistry Research. 2000; 39: 948-954.

25. Guo K, Zhang ZZ, Luo HJ, Dang JX, Qian Z. An innovative approach of the effective mass transfer area in the rotating packed bed. Industrial \& Engineering Chemistry Research. 2014; 53: 4052-4058.

26. Rao DP, Bhowal A, Goswami PS. Process intensification inrotating packed beds (HIGEE): anappraisal. Industrial \& Engineering Chemistry Research. 2004; 43: 1150-1162.

27. Biligetu T, Wang Y, Nishitoba T, Otomo R, Park S, Mochizuki H, Kondo JN, Tatsumi T, Yokoi T. Al distribution and catalytic performance of ZSM-5 zeolites synthesized with various alcohols. Journal of Catalysis. 2017; 353: 1-10.

28. Itani L, Liu Y, Zhang WP, Bozhilov KN, Delmotte L, Valtchev V. Investigation of the physicochemical changes preceding zeolite nucleation in a sodium-rich aluminosilicate gel. Journal of the American Chemical Society. 2009; 131: 10127-10139.

29. Kosanović C, Bosnar S, Subotić B, Svetlicic V, Radić TM, Dražić G, Havancsák K. Study of the microstructure of amorphous aluminosilicate gel before and after its hydrothermal treatment. Microporous and Mesoporous Materials. 2008; 110: 177-185.

30. Valtchev VP, Bozhilov KN. Transmission electron microscopy study of the formation of FAU-type zeolite at room temperature. The Journal of Physical Chemistry B. 2004; 108: 15587-15598.

31. Yang SY, Navrotsky A, Phillips BL. An in situ calorimetric study of the synthesis of FAU zeolite. Microporous and Mesoporous Materials. 2001; 46: 137-151.

32. Bauer F, Geidel E, Peuker Ch, Pilz W. Vibrational spectra of ${ }^{18}$ O-exchanged NaZSM-5 and HZSM-5. Zeolite. 1996; 17: 278-282.

33. Mintova S, Olson NH, Valtchev V, Bein T. Mechanism of zeolite A nanocrystal growth from colloids at room temperature. Science. 1999; 283: 958-960.

34. Aiello R, Crea F, Nastro A, Subotić B, Testa F. Influence of cations on the physicochemical and structural properties of aluminosilicate gel precursors. Part 1. Chemical and thermal properties. Zeolite. 1991; 11: 767-775.

35. Shirazi L, Jamshidi E, Ghasemi MR. The effect of Si/Al ratio of ZSM-5 zeolite on its morphology, acidity and crystal size. Crystal Research and Technology. 2008; 43: 1300-1306.

36. Fu DL, Schmidt J, Ristanović Z, Chowdhury AD, Meirer F, Weckhuysen BM. Highly oriented growth of catalytically active zeolite ZSM-5 films with a broad range of Si/Al ratios. Angewandte Chemie International Edition. 2017; 129: $11369-11373$.

37. Malfait WJ, Xue XY. The nature of hydroxyl groups in aluminosilicate glasses: Quantifying Si-OH and $\mathrm{Al}-\mathrm{OH}$ abundances along the $\mathrm{SiO}_{2}-\mathrm{NaAlSiO}_{4}$ join by ${ }^{1} \mathrm{H},{ }^{27} \mathrm{Al}-{ }^{1} \mathrm{H}$ and ${ }^{29} \mathrm{Si}^{-1} \mathrm{H}$ NMR spectroscopy. Geochimica et Cosmochimica Acta. 2010; 74: 719-737.

38. Dib E, Mineva T, Veron E, Sarou-Kanian V, Fayon F, Alonso B. ZSM-5 zeolite: complete al bond connectivity and implications on structure formation from solid-state NMR and quantum chemistry calculations. The Journal of Physical Chemistry Letters. 2018; 9: 19-24.

39. Valtchev VP, Bozhilov KN. Evidences for zeolite nucleation at the solid-liquid interface of gel cavities. Journal of the American Chemical Society. 2005; 127: 16171-16177.

40. Wang YX, Song JJ, Baxter NC, Kuo GT, Wang SN. Synthesis of hierarchical ZSM-5 zeolites by solidstate crystallization and their catalytic properties. Journal of Catalysis. 2017; 349: 53-65.

41. Wang YQ, Wu QM, Meng XJ, Xiao FS. Insights into the organotemplate-free synthesis of zeolite catalysts. Engineering, 2017; 3: 567-574.

42. Liu BY, Xie KH, Oh SC, Sun DL, Fang YX, Xi HX. Direct synthesis of hierarchical USY zeolite for retardation of catalyst deactivation. Chemical Engineering Science. 2016; 153: 374-381.

43. Yang ZX, Xia YD, Mokaya R. Zeolite ZSM-5 with unique supermicropores synthesized using mesoporous carbon as a template. Advanced Materials. 2004; 16: 727-732.

44. Xing AH, Yuan DL, Tian DY, Sun Q. Controlling acidity and external surface morphology of SAPO-34 and its improved performance for methanol to olefins reaction. Microporous and Mesoporous Materials. 2019; 288: 109562.

45. Rodríguez-González L, Hermes F, Bertmer M, Rodríguez-Castellón E, Jiménez-López A, Simon U. The acid properties of H-ZSM-5 as studied by $\mathrm{NH}_{3}$-TPD and ${ }^{27} \mathrm{Al}-\mathrm{MAS}-\mathrm{NMR}$ spectroscopy. Applied 
Catalysis A: General. 2007; 328: 174-182.

46. Na K, Alayoglu S, Ye R, Somorjai GA. Effect of acidic properties of mesoporous zeolites supporting Pt nanoparticles on hydrogenative conversion of methylcyclopentane. Journal of the American Chemical Society. 2014; 136: 17207-17212.

47. Wang N, Hou YL, Sun WJ, Cai DL, Chen ZH, Liu LM, Ge BH, Hu L, Qian WZ, Wei F. Modulation of baxis thickness within MFI zeolite: Correlation with variation of product diffusion and coke distribution in the methanol-to-hydrocarbons conversion. Applied Catalysis B: Environmental. 2019; 243: 721-733.

48. Lou Y, Ma J, Hu WD, Dai QG, Wang L, Zhan WC, Guo YL, Cao XM, Guo Y, Hu P, Lu GZ. Lowtemperature methane combustion over Pd/H-ZSM-5: active Pd sites with specific electronic properties modulated by acidic sites of H-ZSM-5. ACS Catalysis. 2016; 6: 8127-8139.

49. Shi J, Zhao GL, Teng JW, Wang YD, Xie ZK. Morphology control of ZSM-5 zeolites and their application in Cracking reaction of C4 olefin. Inorganic Chemistry Frontiers. 2018; 5: 2734-2738.

\section{Hosted file}

Image.docx available at https://authorea.com/users/336910/articles/462582-effects-ofenhancing-micromixing-on-nucleation-crystal-growth-process-and-material-propertiesof-zeolite

\section{Hosted file}

Table.docx available at https://authorea.com/users/336910/articles/462582-effects-ofenhancing-micromixing-on-nucleation-crystal-growth-process-and-material-propertiesof-zeolite 